\title{
The Aromatase Knock-Out Mouse Provides New Evidence That Estradiol Is Required during Development in the Female for the Expression of Sociosexual Behaviors in Adulthood
}

\author{
Julie Bakker, ${ }^{1}$ Shin-Ichiro Honda, ${ }^{2}$ Nobuhiro Harada, ${ }^{2}$ and Jacques Balthazart ${ }^{1}$ \\ ${ }^{1}$ Center for Cellular and Molecular Neurobiology, Research Group in Behavioral Neuroendocrinology, University of Liège, \\ B-4020 Liège, Belgium, and 2Division of Molecular Genetics, Fujita Health University, Toyoake, 470-11 Aichi, Japan
}

\begin{abstract}
We used estrogen-deficient aromatase knock-out (ArKO) mice to determine whether estrogens contribute to the development of the brain and behavior in females. Female mice of three different genotypes [i.e., wild type (WT), heterozygous (HET), and homozygous (ArKO)] were ovariectomized in adulthood and subsequently tested for odor preferences (choice: intact male vs estrous female) in a Y-maze. When treated with testosterone, ArKO females spent significantly less time sniffing odors (both volatile and nonvolatile) from either male or female stimuli compared with WT and HET females. When given direct access to anesthetized stimulus animals or when given a choice between odor and visual cues from both stimulus animals, ArKO females continued to spend less time investigating the stimuli compared with WT and HET females. These defects in olfactory investigation of ArKO females were partially corrected with estradiol treatment in adulthood. Estradiol-treated ArKO fe-
\end{abstract}

The early anatomical and physiological work of Jost (for review, see Jost, 1985) showed that fetal gonadectomy of male and female rabbit fetuses results in both sexes developing female internal and external genitalia. It was concluded that the female phenotype develops in the absence of any hormonal secretion from the ovaries, whereas the male phenotype results from the secretion of testosterone and antimüllerian hormone, both secreted by the fetal testes. Additional experiments (Phoenix et al., 1959) demonstrated that the sexual differentiation of the brain follows a similar pattern; i.e., testosterone secreted by the testes causes masculinization (enhancement of male-typical sexual responses) and defeminization (suppression of female-typical sexual responses) of the neural substrates mediating sexual behavior. For instance, female guinea pigs treated with testosterone propionate in utero showed elevated levels of male sexual responses (i.e., mounting behavior) and reduced levels of female sexual responses (i.e., lordosis) in adulthood (Phoenix et al., 1959). The absence of testosterone produced opposite effects (i.e., demasculinization and feminization of the brain): females and neonatally castrated male rats (Feder and Whalen, 1965; Grady et al., 1965) show diminished levels of male sexual behaviors after adult

Received Feb. 20, 2002; revised June 3, 2002; accepted July 3, 2002.

This work was supported by French Community of Belgium Grant ARC 99/04-241 and National Institutes of Health Grant MH-50388.

Correspondence should be addressed to Dr. Julie Bakker, Center for Cellular and Molecular Neurobiology, Research Group in Behavioral Neuroendocrinology, University of Liège, 17 Place Delcour (Bat L1), B-4020 Liège, Belgium. E-mail: jbakker@ulg.ac.be.

Copyright @ 2002 Society for Neuroscience $0270-6474 / 02 / 229104-09 \$ 15.00 / 0$ males no longer differed from WT and HET females in the time spent investigating either nonvolatile odors or the anogenital region of anesthetized animals. However, ArKO females still investigated volatile odors and/or visual cues less than WT and HET females. Sexual receptivity was severely impaired in ArKO females after treatments with estradiol and progesterone that successfully induced receptivity in WT and HET females. Furthermore, ArKO females showed diminished levels of male sexual behaviors, whereas WT and HET females readily mounted an estrous female. Together, these findings demonstrate that estrogen is required for normal female development. The concept that the female brain develops in the absence of any hormonal stimulation should therefore be reconsidered.

Key words: aromatase; olfaction; sex; behavior; preference; development

testosterone treatment and high levels of lordosis behavior after adult treatment with estradiol and progesterone. Thus, the female brain seems to develop in the absence of any hormonal secretion. In contrast to the sexual differentiation of the genitalia, many of the masculinizing and defeminizing effects of perinatal testosterone on the brain are mediated by estradiol derived from local aromatization of testosterone (Naftolin et al., 1975; McEwen et al., 1977; Baum, 1979; MacLusky and Naftolin, 1981).

The concept of female differentiation proceeding in the absence of any hormonal secretion, however, is challenged by several observations. First, Toran-Allerand (1976) demonstrated that hypothalamic neurons of newborn mice of both sexes develop neurite processes in vitro only when estradiol is added to the culture medium. Second, Döhler et al. (1984) found that postnatal treatment of female rats with tamoxifen, an estrogen receptor antagonist, defeminized both gonadotropin regulation and female sexual behavior, whereas concurrent administration of low doses of estradiol prevented these effects of tamoxifen. Finally, Mack et al. (1993) found that estrogen action is required in females for a normal, female-like development of the corpus callosum, a cortical structure that is larger in male than in female rats. Ovariectomy of female rats as late as day 16 after birth increased the cross-sectional area of the adult corpus callosum (i.e., made it more male-like), whereas treatment with estradiol in a low dose starting at day 25 after birth inhibited this effect (Fitch and Denenberg, 1998). Together, these findings suggest that estrogens are required during development to feminize the brain. In the present study, we tested this concept by determining whether sociosexual behaviors are disrupted in female mice that 
have been depleted of estrogens during the critical period of development by targeted disruption of the aromatase (Cyp19) gene [aromatase knock-out (ArKO) mice] (Honda et al., 1998).

\section{MATERIALS AND METHODS}

Subjects and general procedures

ArKO mice were generated by targeted disruption of exons 1 and 2 of the Cyp19 gene (Honda et al., 1998). Heterozygous (HET) males and females of the C57BL/6 strain were bred to generate wild-type (WT), HET, and homozygous-null (ArKO) offspring. Mice were genotyped by PCR analysis of tail DNA (Bakker et al., 2002). All breeding and genotyping were performed at the School of Veterinary Medicine of the University of Liège. During behavioral testing, all experimental mice were housed alone under reversed light/dark cycle (12 light/dark, lights off at 9:00 A.M.). Food and water were always available ad libitum. All experiments were conducted in accordance with the guidelines set forth by the National Institutes of Health Guiding Principles for the Care and Use of Research Animals and were approved by the Ethical Committee for Animal Use of the University of Liège.

At the age of $\sim 20$ weeks, 24 females (eight of each genotype: WT, HET, and ArKO) were ovariectomized under general anesthesia with a mixture of ketamine $(173 \mu \mathrm{g} / \mathrm{gm}$ per mouse) and xylazine $(6 \mu \mathrm{g} / \mathrm{gm}$ per mouse). At the time of ovariectomy, a 5-mm-long Silastic capsule (inner diameter, $1.57 \mathrm{~mm}$; outer diameter, $2.41 \mathrm{~mm}$ ) filled with crystalline testosterone was implanted subcutaneously in the neck. Stimulus animals (males and females) were derived from a different breeding colony of the Naval Medical Research Institute strain at the University of Liège. Stimulus males were left gonadally intact. All stimulus females were ovariectomized and injected subcutaneously 48 and $24 \mathrm{hr}$ before testing with estradiol benzoate $(1.25 \mathrm{mg} / \mathrm{kg}$ mouse; dissolved in sesame oil) followed by progesterone ( $1 \mathrm{mg}$ per mouse; dissolved in sesame oil) $3 \mathrm{hr}$ before testing.

All behavioral tests were conducted between 1:00 and 6:00 P.M. during the dark phase of the light/dark cycle. Furthermore, no behavioral testing was conducted during the $24 \mathrm{hr}$ after the subjects' cages were cleaned.

\section{Odor-preference tests}

Description Y-maze. All preference tests were conducted in an enclosed, Plexiglas Y-maze (adapted for mice according to Petrulis and Johnston, 1999). The Y-maze consisted of the stem of the Y $(55 \mathrm{~cm}$ long) and two arms $\left(65 \mathrm{~cm}\right.$ long) that diverged at a $60^{\circ}$ angle from the stem. All parts of the maze were $9 \mathrm{~cm}$ high and $9 \mathrm{~cm}$ wide. A removable perforated Plexiglas door at the distal end of the each arm separated the goal box from the rest of the maze. We used either an opaque (to prevent visual cues) or a clear (to allow visual cues) Plexiglas door. A perforated Plexiglas door was placed at the other side of the goal box. The start box with a removable perforated Plexiglas door was located at the base of the stem. An electric fan was placed behind the start box, from which it was separated by a wire screen. The perforated doors and the fan made it possible to pull air over odor stimuli placed in the distal goal boxes through the entire maze into the start box.

Test procedure. All subjects were housed alone starting at the time of ovariectomy. Their cages were placed at random in a climate-controlled (light, temperature, and ventilation) animal housing unit (Iffa-Credo, Arbresle, France). Stimulus males and females were always housed in a different animal housing unit, so subjects were never exposed to any male- or estrous female-derived odors except when they were tested. For each test, cages were taken randomly out of the housing unit to avoid the possibility that the same animals would always be tested first or last. At the beginning of each test, the subject was placed in the start box with the door closed to adapt for $1 \mathrm{~min}$. The test began when the door was removed and the subject could move around freely in the Y-maze. All female subjects were tested three times (5 min each) in the Y-maze without any stimulus animals in the goal boxes to adapt to the testing apparatus and to determine whether they would develop any side preferences.

\section{Experimental procedures}

Experiment 1: contribution of the aromatase gene to the development of odor preferences

Approximately 5 weeks after ovariectomy and implantation of a Silastic capsule containing testosterone, female mice of each genotype (WT, HET, and ArKO) were subjected to a series of odor-preference tests using different stimuli (see description below). Subsequently, after 4 weeks of testing, the testosterone capsule was replaced by a 5-mm-long SILASTIC capsule (inner diameter, $1.57 \mathrm{~mm}$; outer diameter, $2.41 \mathrm{~mm}$ ) containing crystalline $17 \beta$-estradiol (diluted 1:1 with cholesterol) under ketamine/xylazine anesthesia. The capsules were approximately the same size as those used by Wersinger et al. (1999), which resulted in levels of estradiol slightly lower $(80 \mathrm{pg} / \mathrm{ml})$ than the levels observed during estrus $(150 \mathrm{pg} / \mathrm{ml})$. The inner and outer diameters of our capsules, however, were slightly larger than those used by Wersinger et al. (inner diameter, $1.02 \mathrm{~mm}$; outer diameter, $2.16 \mathrm{~mm}$ ), resulting in a decreased thickness (outside minus inside diameter $=0.78 \mathrm{~mm}$ here vs $1.14 \mathrm{~mm}$ ) and increased surface $\left(\pi \times\right.$ outside diameter $\times$ length $=37.85 \mathrm{~mm}^{2}$ here vs $33.92 \mathrm{~mm}^{2}$ ). Because the amount of steroid released from a Silastic implant is directly proportional to the surface of the capsule and inversely related to its thickness (Smith et al., 1977), it can be roughly estimated that our capsules produced circulating levels of estradiol of $\sim 130 \mathrm{pg} / \mathrm{ml}$ [i.e., 1.63 times higher, $(1.14 / 0.78) \times(37.85 / 33.92)$, than in Wersinger et al. (1999)]. These levels are in the range of values observed during estrus in mice (Wersinger et al., 1999). After 3 weeks of estradiol treatment, behavioral testing was resumed, and female mice were subjected to the same series of odor-preference tests (which lasted $\sim 3$ weeks) in the same order as had been used while they were on testosterone. To facilitate comparisons, the data obtained while subjects were treated with testosterone are presented in Results side by side with those obtained while the subjects were treated with estradiol.

Volatile olfactory cues. First, female mice were subjected to two consecutive tests ( 5 min each) in which they were offered a choice between volatile odors of an estrous female versus those of a gonad-intact male. The Plexiglas doors separating the goal boxes from the rest of the maze were opaque to prevent the subjects from seeing the stimulus animals. In addition, stimulus animals were anesthetized with ketamine/xylazine to prevent them from producing sounds that could be detected by the test animal. The level of anesthesia was checked and adjusted between each trial. Stimulus animals were regularly placed on a heating pad to prevent hypothermia. The position of the stimulus animals was switched between tests. The time the subject spent sniffing the male and female odors (poking its nose through the holes of the door and actively sniffing the door of the goal box) was recorded with a stopwatch. In addition, the number of entries into each arm was scored. The maze was cleaned with $70 \%$ alcohol between trials.

Soiled bedding. Second, female mice were subjected to one $5 \mathrm{~min}$ test in which they were given a choice between soiled bedding from gonadintact males versus soiled bedding from estrous females. Stimulus females $(n=3)$ injected twice with estradiol benzoate subcutaneously (48 and $24 \mathrm{hr}$ before bedding was collected) and subsequently with progesterone were placed in a cage containing fresh sawdust. Bedding was collected $10 \mathrm{hr}$ after the progesterone injection. Likewise, gonad-intact males $(n=3)$ were placed in a cage containing fresh sawdust. Bedding was collected $10 \mathrm{hr}$ later. All bedding was stored in plastic freezer bags at $-70^{\circ} \mathrm{C}$ until used in the experiment. Bowls containing soiled bedding were placed at the end of each arm of the Y-maze. The doors separating the goal boxes from the rest of the maze were removed. The time the mice spent sniffing the bedding was recorded for each subject. The maze was cleaned with $70 \%$ alcohol between trials.

Direct access to stimulus animals. Third, female mice were given one 5 min test in which they had direct access to a gonad-intact male and an estrous female. Stimulus animals were anesthetized to eliminate any interference of the behavioral interaction between the subjects and the stimulus animals. The doors separating the goal boxes from the rest of the maze were removed. The time each subject spent sniffing the stimulus animal, including its anogenital region and flank, was recorded with a stopwatch. The maze was cleaned with $70 \%$ alcohol between each trial. As in Experiment 1, the level of anesthesia was checked regularly and adjusted between each trial if necessary. Furthermore, stimulus animals were regularly placed on a heating pad to prevent hypothermia.

Odor and visual cues. Finally, female subjects were given one 5 min test in which they could choose between an awake gonad-intact male and an awake estrous female. Stimulus animals were placed behind a clear Plexiglas door. Subjects could thus see, smell, and hear but not physically interact with the stimulus animals. The time the subject spent sniffing the male and female odors (poking its nose through the holes of the door and actively sniffing the door of the goal box) was recorded with a stopwatch. The maze was cleaned with $70 \%$ alcohol between each trial. 


\section{Experiment 2: contribution of the aromatase gene to the development of lordosis behavior}

At the end of preference testing, female subjects were tested once a week during 5 weeks for lordosis behavior with a sexually active male. Females were $\sim 35$ weeks of age and had received estradiol treatment for $>6$ weeks. All female subjects continued to receive estradiol treatment and in addition were injected subcutaneously with $1 \mathrm{mg}$ of progesterone $3 \mathrm{hr}$ before each lordosis test. All lordosis tests were conducted in a Plexiglas aquarium (35 cm long $\times 25 \mathrm{~cm}$ high $\times 19 \mathrm{~cm}$ wide) whose floor was covered with fresh sawdust. At the beginning of each test, a sexually active male was placed alone in the aquarium and allowed to adapt for 15 min. Subsequently, an experimental female was placed in the aquarium, and the lordosis responses of the female to the mounts of the stimulus male were recorded. The receptivity of each female to the males' mounts was also scored on an ordinal 4 point scale as follows: 1 , female ran away and/or responded aggressively; 2 , female did not run away but rejected the mount; 3 , female accepted the mount but did not respond by showing lordosis; and 4, female responded by showing lordosis. The test lasted until the female had received 10 mounts or $10 \mathrm{~min}$ had elapsed.

\section{Experiment 3: olfaction test}

Two "hidden cookie" tests were conducted to check for gross malfunction of the main olfactory system in female ArKO mice. All female mice were food-deprived overnight $(\sim 24 \mathrm{hr})$. A small piece of a chocolate chip cookie was buried $(\sim 1 \mathrm{~cm}$ deep) at a random location in a clean Plexiglas aquarium ( $35 \mathrm{~cm}$ long $\times 25 \mathrm{~cm}$ high $\times 19 \mathrm{~cm}$ wide) containing fresh sawdust. The time it took each mouse to find the cookie was recorded. The test lasted until the mouse had located the cookie or $15 \mathrm{~min}$ if the cookie was not found. Mice were tested twice $4 \mathrm{~d}$ apart. At the time of these tests, which were performed 1 week after completion of the lordosis tests, mice still had their Silastic capsules containing estradiol.

\section{Experiment 4: open-field test}

All female subjects were tested for general locomotor activity in an open field (clean Plexiglas cage; $51 \mathrm{~cm}$ long $\times 18 \mathrm{~cm}$ high $\times 30 \mathrm{~cm}$ wide). The cage was divided into nine rectangles $(17 \times 10 \mathrm{~cm})$. At the beginning of the test, the subject was placed in the middle of the cage. The number of crossings (from one rectangle to another) was recorded. We considered the line crossed when all four legs were over the line. The time spent in each square was also recorded. Females were tested once for 5 min. At the time of this test (1 week after completion of the olfaction tests), mice still had their Silastic capsules containing estradiol.

\section{Experiment 5: contribution of the aromatase gene to the development of male sexual behavior}

Previous work on another strain of ArKO mice has indicated that these mice are exposed to increased plasma levels of testosterone during adulthood (Fisher et al., 1998). These increased levels of androgens could result from the interruption of the steroid feedback on gonadotropin secretion, which is known to be mediated in part by estrogens, as suggested by the increased levels of circulating luteinizing hormone and follicle-stimulating hormone in these mice. Alternatively, the increase in plasma testosterone could be caused, at least in part, by the accumulation of the androgenic substrate, which can no longer be transformed into an estrogen by the ovaries because of the disruption of the aromatase gene. Because the fetal and neonatal ovaries are not (very) active (Weniger, 1993; Weniger et al., 1993), it is unlikely that this increase in androgen levels actually takes place before puberty, but no data are available to evaluate this question, and it could therefore be speculated that increased levels of androgens contribute to the development of the behavioral phenotype in ArKO mice. To determine whether the absence of lordosis behavior in ArKO females did not result from masculinization and defeminization of their brains by excessive androgen action during development, a different set of female ArKO mice was tested for maletypical sexual behavior with an estrous female. At the age of $\sim 12$ weeks, female mice of three different genotypes (10 WT, 7 HET, and 9 ArKO) were ovariectomized in adulthood under general anesthesia. At the same time, a 5-mm-long Silastic capsule (inner diameter, $1.57 \mathrm{~mm}$; outer diameter, $2.41 \mathrm{~mm}$ ) filled with crystalline testosterone was implanted subcutaneously in the neck. After 7 weeks of testosterone treatment, females were tested once for male-typical sexual behavior. To determine whether the absence of male sexual behavior in ArKO females was a result of a lack of circulating estradiol, females were tested once more for male-typical sexual behavior after receiving daily injections of estradiol benzoate ( $5 \mu \mathrm{g}$ per mouse) for 2 weeks while remaining on testosterone. All coital behavior tests were conducted in a Plexiglas aquarium $(35 \mathrm{~cm}$ long $\times 25 \mathrm{~cm}$ high $\times 19 \mathrm{~cm}$ wide) whose floor was covered with fresh sawdust. At the beginning of each test, the female subject was placed alone in the aquarium to adapt for $15 \mathrm{~min}$. Subsequently, an estrous female was introduced, and the number of mounts and intromission-like behaviors displayed by the female subject were scored for $30 \mathrm{~min}$. In addition, latencies to mounts and intromission-like behaviors were recorded. The female subject was never mounted by the stimulus female. Furthermore, ejaculation-like behavior of the female subjects was never observed.

\section{Statistical analysis}

For experiments 1-4, three WT females that did not survive the second round of anesthesia when the testosterone capsule was replaced by one capsule containing estradiol and two ArKO females (one died and one ceased to explore the Y-maze in the course of behavioral testing) were excluded from statistical analysis. All data were analyzed using repeatedmeasures ANOVA with various independent and repeated factors. First, all data obtained while subjects were treated with testosterone were directly compared with those obtained while subjects were treated with estradiol in one large multifactor ANOVA. Subsequently, the data were analyzed separately for each hormone treatment to simplify the presentation of the results. Therefore, in each section of Results, the data obtained while subjects were treated with testosterone are presented first, followed by those obtained while subjects were treated with estradiol, and finally, the two different hormone treatments are compared. All male coital data (experiment 5) were analyzed in one ANOVA. When appropriate, all ANOVAs were followed by Tukey highly significant difference post hoc comparisons adapted for repeated-measures ANOVA. Only significant $(p<0.05)$ effects detected by the ANOVA are mentioned in detail in Results.

\section{RESULTS}

\section{Experiment 1: contribution of the aromatase gene to the development of odor preferences}

\section{Clean Y-maze}

No side preferences were detected when subjects were tested without any stimulus animals placed in the goal boxes of the Y-maze. A three-way ANOVA of the time spent in each arm of the maze with genotypes as the independent factor and tests and side of the Y-maze (left vs right) as repeated factors showed a significant effect only of repeated testing $\left(F_{(2,32)}=7.29 ; p=\right.$ $0.0025)$, but neither an effect of genotype $\left(F_{(2,16)}=0.96 ; p=0.40\right)$ nor an effect of side of the Y-maze $\left(F_{(1,16)}=1.89 ; p=0.19\right)$ nor any significant interactions. Post hoc analysis of the test effect showed that all subjects spent more time in the arms of the Y-maze in the second than the first test (mean \pm SEM for all three genotypes; $55.5 \pm 3.6$ vs $69.2 \pm 4.3 \mathrm{sec}$ for test 1 vs test 2 , respectively). The number of arm entries did not differ significantly between genotypes, although there was a trend toward a decrease in ArKO females (mean \pm SEM: WT, $4.7 \pm 0.4$; HET, $\left.4.9 \pm 0.3 ; \operatorname{ArKO}, 3.2 \pm 0.2 ; F_{(2,16)}=2.77 ; p=0.09\right)$.

\section{Volatile olfactory cues}

Testosterone treatment. WT females clearly preferred to sniff volatile odors from an estrous female over those from a sexually active male. This preference for female odors was less evident in HET and ArKO females (Fig. 1 $A$ ). A three-way ANOVA of the time spent sniffing volatile odors with genotype as the independent factor and tests and odor stimulus (male vs female) as repeated factors revealed a significant effect of genotype $\left(F_{(2,16)}\right.$ $=22.70 ; p=0.0001)$, a significant effect of odor stimulus $\left(F_{(1,16)}\right.$ $=12.99 ; p=0.0024)$, a significant odor stimulus by genotype interaction $\left(F_{(2,16)}=6.41 ; p=0.009\right)$, and a significant test by odor stimulus interaction $\left(F_{(1,16)}=19.80 ; p=0.0004\right)$. Because we found neither a significant effect of repeated testing $\left(F_{(1,16)}=\right.$ 


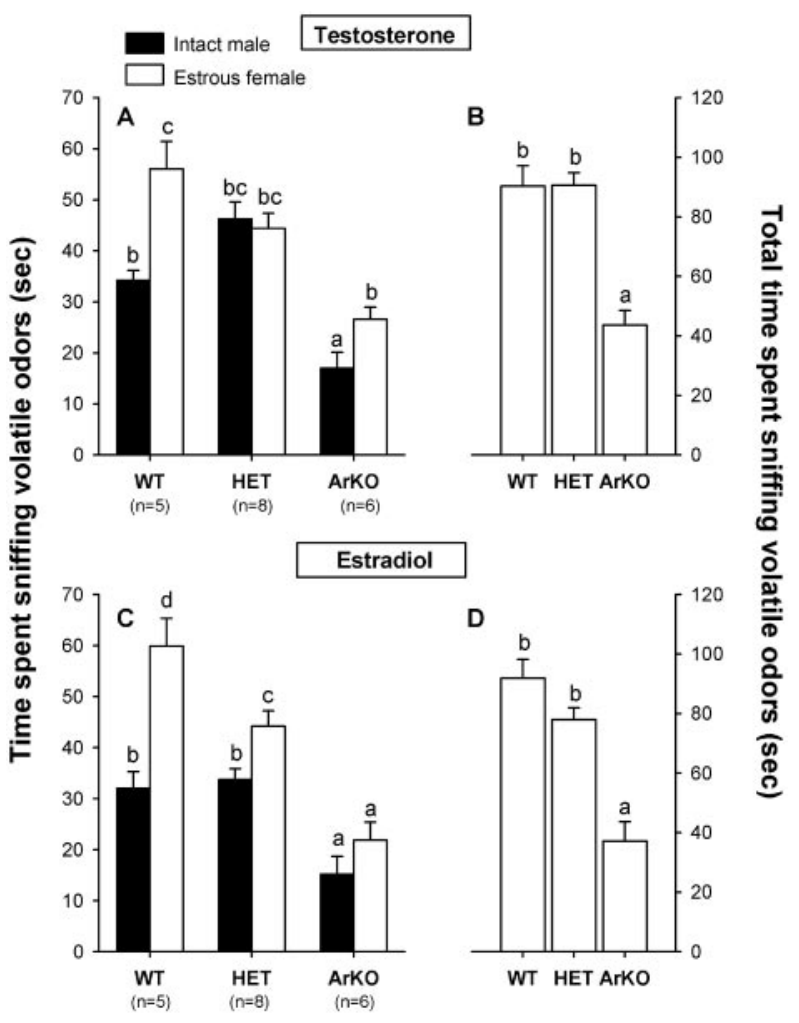

Figure 1. A, C, Mean amount of time that female WT, HET, and ArKO mice spent investigating volatile olfactory cues when given a choice between intact male odors and estrous female odors in a Y-maze. $B, D$, Total amount of time spent sniffing volatile odors. $A, B$, Results when subjects were treated with testosterone. $C, D$, Results when the same subjects were treated with estradiol. Means with different letters above them are significantly different from each other by post hoc comparisons. Data shown are the mean \pm SEM of two successive behavior tests.

$0.73 ; p=0.41)$ nor a significant test by genotype interaction $\left(F_{(2,16)}=0.05 ; p=0.95\right)$, data of two preference tests were combined (Fig. 1A,B). Post hoc analysis of the genotype effect showed that female ArKO mice spent less time sniffing volatile odors (either male or female) than WT and HET mice (Fig. 1B). Furthermore, post hoc analysis of the odor stimulus by genotype interaction showed that WT and ArKO females spent significantly more time sniffing female odors than male odors, whereas HET females spent equal time sniffing both odors. Finally, post hoc analysis of the significant test by odor stimulus interaction showed that all female groups spent less time sniffing male odors and more time sniffing female odors in the second than the first test.

Three-way ANOVA on the number of entries into each arm of the Y-maze with genotype as the independent factor and tests and odor stimuli (male vs female) as repeated factors showed a significant effect only of genotype $\left(F_{(2,16)}=8.56 ; p=0.003\right)$. ArKO females made fewer arm entries than WT and HET females (mean \pm SEM: $5.4 \pm 0.3$ for ArKO females vs $10.7 \pm 1.3$ for WT females and $11.6 \pm 1.2$ for HET females).

Estradiol treatment. WT females continued to show a preference for sniffing volatile odors from an estrous female. This preference to investigate female odors was less pronounced in HET females, whereas ArKO females showed no significant preference (Fig. 1C). Three-way ANOVA of time spent sniffing volatile odors with genotype as the independent factor and tests and odor stimulus (male vs female) as repeated factors showed a significant effect of genotype $\left(F_{(2,16)}=20.85 ; p=0.0001\right)$, a significant effect of odor stimulus $\left(F_{(1,16)}=33.46 ; p=0.0001\right)$, a significant odor stimulus by genotype interaction $\left(F_{(2,16)}=5.64\right.$; $p=0.014)$, a significant test by stimulus interaction $\left(F_{(1,16)}=\right.$ $9.00 ; p=0.009)$, and a significant test by stimulus by genotype interaction $\left(F_{(2,16)}=3.81 ; p=0.04\right)$. Because we found neither an effect of repeated testing $\left(F_{(1,16)}=0.01 ; p=0.91\right)$ nor a significant test by genotype interaction $\left(F_{(2,16)}=0.02 ; p=0.98\right)$, we combined data for two tests (Fig. $1 C, D$ ). Post hoc analysis of the genotype effect showed that the total time spent sniffing volatile odors (either male or female) was again reduced in ArKO females compared with WT and HET females (Fig. 1D). Furthermore, post hoc analysis of the odor stimulus by genotype interaction revealed that WT females spent more time sniffing female odors compared with HET females, which, in turn, spent more time sniffing female odors compared with ArKO females. In addition, WT and HET females spent more time sniffing male odors compared with ArKO females (Fig. 1C). Finally, post hoc analysis of the test by stimulus and the test by stimulus by genotype interactions revealed that HET females (but not WT and ArKO females) spent more time sniffing male odors and less time sniffing female odors in the second than the first preference test (data not shown).

Three-way ANOVA on the number of arm entries with genotype as the independent factor and tests and odor stimulus as repeated factors showed a significant effect of genotype $\left(F_{(2,16)}=5.80 ; p=0.013\right)$, a significant effect of repeated testing $\left(F_{(1,16)}=21.82 ; p=0.0003\right)$, a significant effect of odor stimulus $\left(F_{(1,16)}=9.64 ; p=0.007\right)$, an almost significant stimulus by genotype interaction $\left(F_{(2,16)}=3.12 ; p=0.07\right)$, and an almost significant test by stimulus interaction $\left(F_{(2,16)}=4.25\right.$; $p=0.06)$. Again, ArKO females made fewer arm entries than WT and HET females (mean \pm SEM: $5.6 \pm 1.0$ for ArKO females vs $12.2 \pm 1.3$ for WT females and $12.2 \pm 1.6$ for HET females). Furthermore, all female groups made fewer arm entries in the second than the first test (no significant test by genotype interaction: $\left.F_{(2,16)}=0.21 ; p=0.82\right)$.

Testosterone versus estradiol treatment. In comparing the effects of hormone treatment on time spent sniffing volatile odors, fourway ANOVA with genotype as the independent factor and hormone treatment, odor stimulus, and tests as repeated factors showed a significant effect of hormone treatment $\left(F_{(1,16)}=5.74\right.$; $p=0.029)$. Post hoc analysis of the hormone effect showed that all females, but particularly HET females (almost significant hormone by genotype interaction: $\left.F_{(2,16)}=2.91 ; p=0.08\right)$, spent less time sniffing volatile odors when treated with estradiol.

\section{Soiled bedding}

Testosterone treatment. All female subjects preferred to investigate soiled bedding from estrous females over bedding from intact males (Fig. 2A). Two-way ANOVA with genotype as the independent factor and odor stimulus (male vs female bedding) as the repeated factor showed a significant effect of genotype $\left(F_{(2,16)}=\right.$ $8.29 ; p=0.0034)$ and a significant effect of odor stimulus $\left(F_{(1,16)}=\right.$ 14.93; $p=0.0014)$. Post hoc analysis of the genotype effect showed that ArKO females spent less time sniffing soiled bedding, either male or female, than WT females (Fig. 2B). Furthermore, all three genotypes spent more time sniffing female bedding than male bedding (because there was no significant odor stimulus by genotype interaction: $\left.F_{(2,16)}=0.96 ; p=0.40\right)$.

Estradiol treatment. The preference to investigate female bedding over male bedding disappeared when female subjects were 


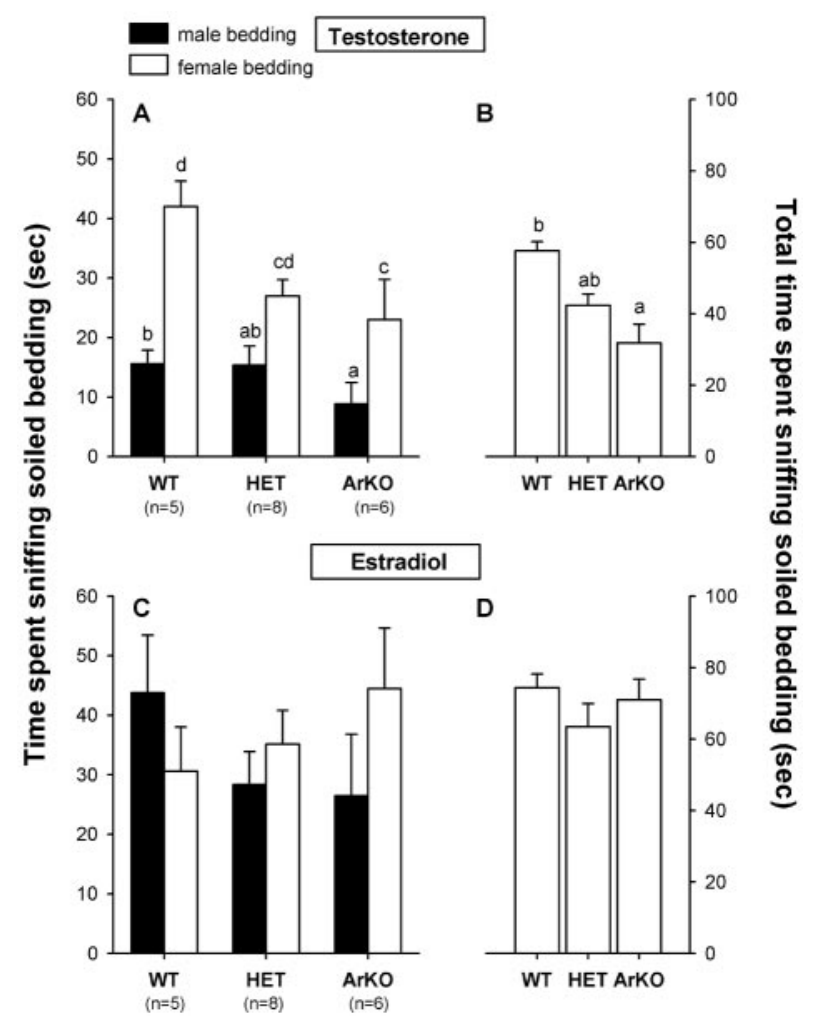

Figure 2. A, C, Mean amount of time that female WT, HET, and ArKO mice spent sniffing nonvolatile olfactory cues when given a choice between soiled bedding from intact males and that from estrous females in a Y-maze. $B, D$, Total amount of time spent sniffing nonvolatile odors. $A$, $B$, Results when subjects were treated with testosterone. $C, D$, Results when the same subjects were treated with estradiol. Means with different letters above them are significantly different from each other by post hoc comparisons.

treated with estradiol (Fig. 2, $C$ vs $A$ ). In addition, all female groups, particularly ArKO, spent more time sniffing soiled bedding when treated with estradiol than when treated with testosterone (Fig. 2, $D$ vs $B$ ). As a result, ArKO females no longer differed from WT and HET females in total time spent sniffing soiled bedding. This was confirmed by two-way ANOVA with genotype as the independent factor and odor stimulus as the repeated factor, showing neither an effect of genotype $\left(F_{(2,16)}=\right.$ $0.79 ; p=0.47)$ nor an effect of odor stimulus $\left(F_{(1,16)}=0.165 ; p=\right.$ $0.69)$.

Testosterone versus estradiol treatment. In comparing the effects of the two hormone treatments, three-way ANOVA with genotype as the independent factor and hormone treatment (testosterone vs estradiol) and odor stimulus as repeated factors revealed a significant effect of hormone treatment $\left(F_{(1,16)}=35.41\right.$; $p=0.0001)$. Post hoc analysis showed that WT and HET females increased their time sniffing male bedding while on estradiol, whereas ArKO females spent more time investigating both types of bedding after treatment with estradiol (Fig. 2, $B$ vs $D$ ).

\section{Direct access to stimulus animals}

Testosterone treatment. No clear preference could be discerned when female subjects were given direct access to an intact male and an estrous female, with both stimulus animals being anesthetized (Fig. 3A). Two-way ANOVA with genotype as the independent factor and odor stimulus as the repeated factor showed a significant effect only of genotype $\left(F_{(2,16)}=4.91 ; p=0.02\right)$. Post

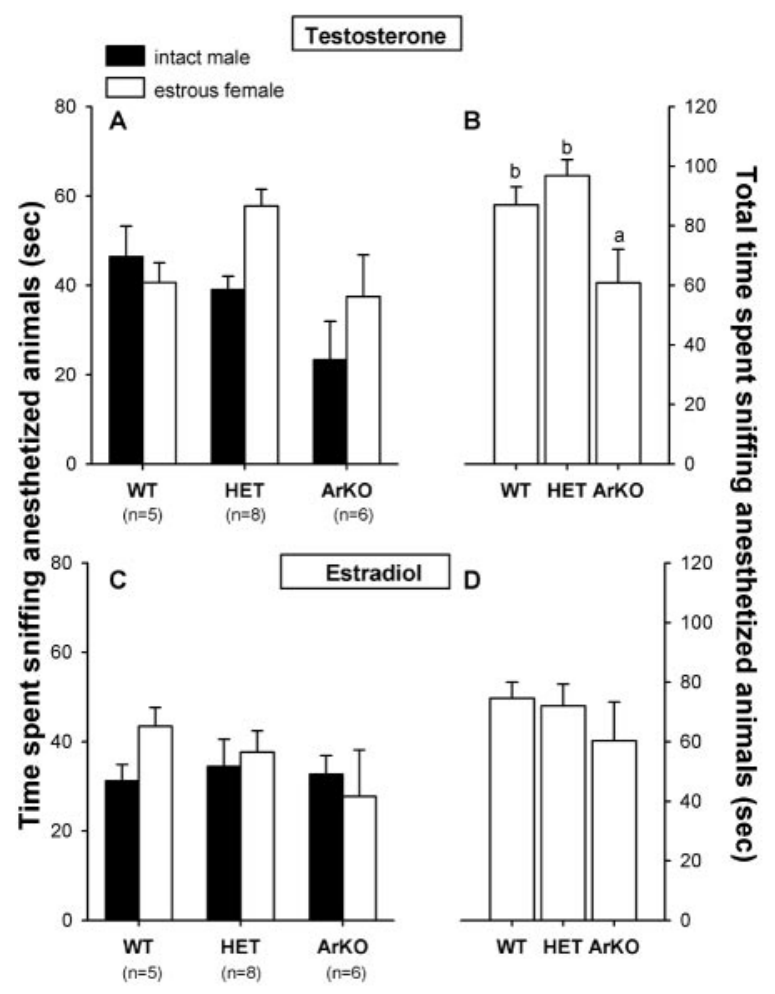

Figure 3. $A, C$, Mean amount of time that female WT, HET, and ArKO mice spent sniffing the anogenital region and flanks when given a choice between an anesthetized intact male and an anesthetized estrous female in a Y-maze. $B, D$, Total amount of time spent sniffing the anogenital region and flanks. $A, B$, Results when subjects were treated with testosterone. $C, D$, Results when the same subjects were treated with estradiol. Means with different letters above them are significantly different from each other by post hoc comparisons.

hoc analysis revealed that ArKO females spent less time investigating the anogenital regions and flanks of the stimulus animals compared with WT and HET females (Fig. 3B).

Estradiol treatment. Again, females of all three genotypes showed no clear preference for either stimulus animal (Fig. 3C). As was observed with the soiled bedding in experiment 1 , ArKO females no longer differed from WT and HET females in total time spent investigating the stimulus animals (Fig. 3D). Accordingly, two-way ANOVA with genotype as the independent factor and odor stimulus as the repeated factor no longer showed a significant effect of genotype $\left(F_{(2,16)}=0.537 ; p=0.59\right)$.

Testosterone versus estradiol treatment. In comparing the effects of hormone treatment on time spent sniffing the stimulus animals, three-way ANOVA with genotype as the independent factor and hormone treatment and odor stimulus as repeated factors revealed a significant effect of hormone treatment $\left(F_{(1,16)}=4.66\right.$; $p=0.05)$. Post hoc analysis showed that all females, but particularly WT and HET females, decreased their time spent sniffing the stimulus animals when treated with estradiol. Thus, in contrast to the findings with the soiled bedding in experiment 1 , in which ArKO females increased their time spent sniffing soiled bedding after treatment with estradiol, WT and HET females decreased their time sniffing the anesthetized stimulus animals after treatment with estradiol, and consequently genotype differences disappeared. 


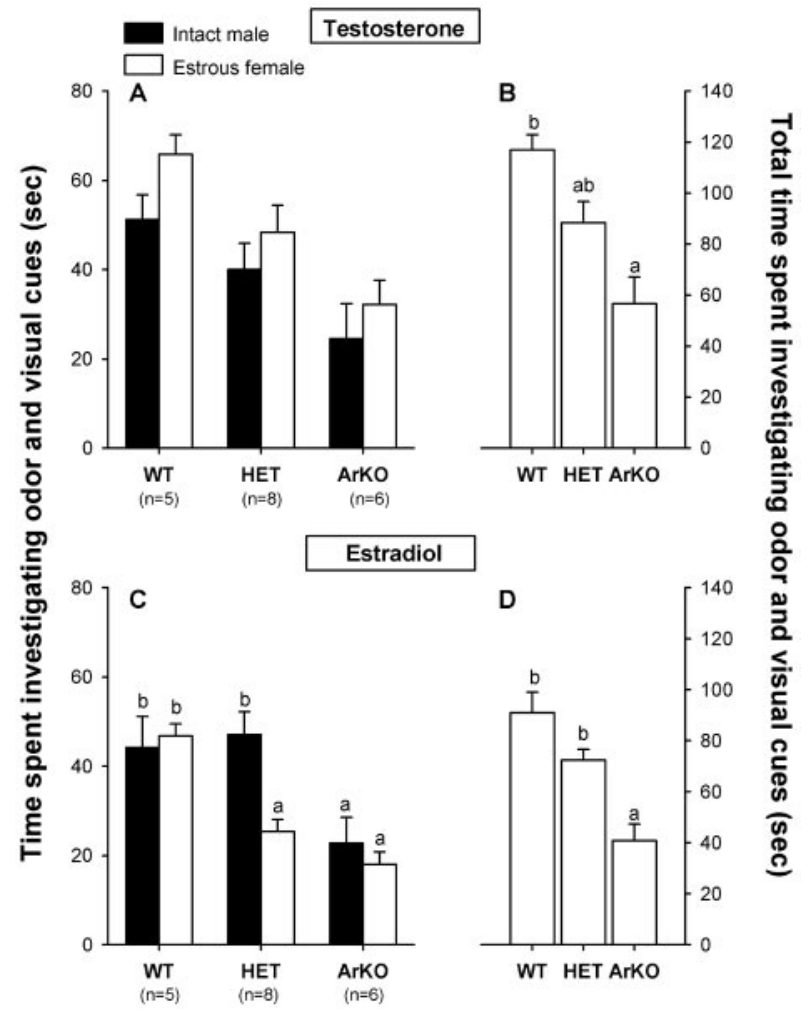

Figure 4. A, C, Mean amount of time that female WT, HET, and ArKO mice spent investigating odor and visual cues when given a choice between an awake intact male and an awake estrous female in a Y-maze. $B$, $D$, Total amount of time investigating odor and visual cues. $A, B$, Results when subjects were treated with testosterone. $C, D$, Results when the same subjects were treated with estradiol. Means with different letters above them are significantly different from each other by post hoc comparisons.

\section{Odor and visual cues}

Testosterone treatment. All female groups showed a weak preference for the estrous female when given a choice between an awake intact male and an awake estrous female placed behind a clear Plexiglas door (Fig. 4A). Two-way ANOVA with genotype as the independent factor and odor stimulus as the repeated factor revealed a significant effect of genotype $\left(F_{(2,16)}=8.72 ; p=\right.$ $0.0027)$ and an almost significant effect of odor stimulus $\left(F_{(1,16)}=\right.$ 3.36; $p=0.085)$. Post hoc analysis of the genotype effect showed that ArKO females spent less time investigating odor and visual cues of either males or females compared with WT females (Fig. $4 B$ ). Post hoc analysis of the effect of odor stimulus showed that subjects of all three genotypes showed a preference, albeit small, to investigate the estrous female instead of the intact male.

Estradiol treatment. HET females preferred to investigate odor and visual cues from an intact male over those from an estrous female, whereas WT and ArKO females showed no preference (Fig. 4C). Two-way ANOVA with genotype as the independent factor and odor stimulus as the repeated factor showed a significant effect of genotype $\left(F_{(2,16)}=13.46 ; p=0.0004\right)$, an almost significant effect of odor stimulus $\left(F_{(1,16)}=3.25 ; p=0.09\right)$, and an almost significant stimulus by genotype interaction $\left(F_{(1,16)}=\right.$ 2.86; $p=0.087)$. Post hoc analysis of the genotype effect showed that ArKO females spent less time investigating odor and visual cues than WT and HET females (Fig. 4D). Furthermore, HET females spent more time investigating the intact male than the
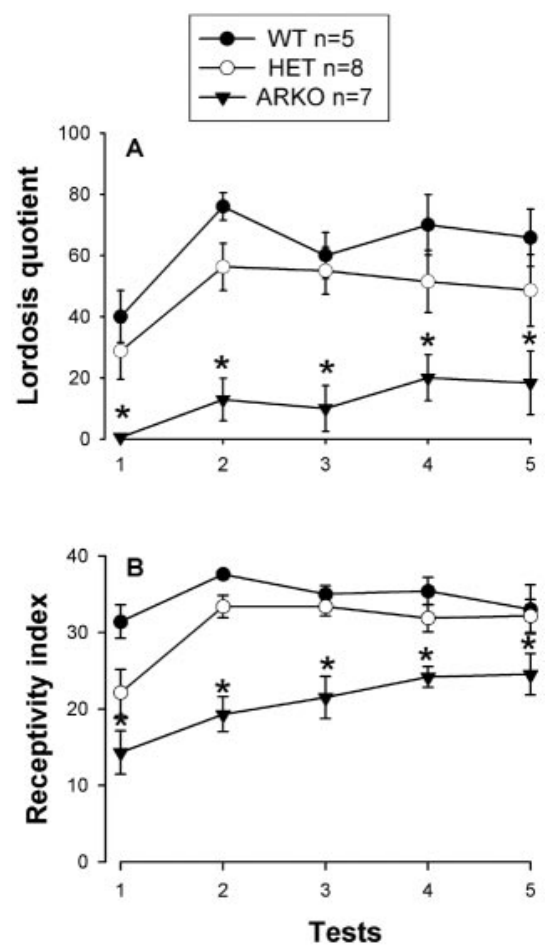

Figure 5. Female sexual behavior with a stud male of female WT, HET, and ArKO mice. $A$, Lordosis quotients; $B$, receptivity index. ${ }^{*} p<0.05$ compared with WT and HET females.

estrous female, whereas WT and ArKO females spent similar amounts of time investigating both stimulus animals.

Testosterone versus estradiol treatment. In comparing the effects of hormone treatment on time spent investigating odor and visual cues, three-way ANOVA with genotype as the independent factor and hormone treatment and odor stimulus as repeated factors showed a significant effect of hormone treatment $\left(F_{(1,16)}=15.59\right.$; $p=0.0012)$ and a significant hormone treatment by stimulus interaction $\left(F_{(1,16)}=8.34 ; p=0.011\right)$. Post hoc analysis of the hormone effect and the interaction showed that all females spent less time investigating odor and visual cues from the estrous female after estradiol treatment (Fig. 4, $A$ vs $C$ ).

\section{Experiment 2: contribution of the aromatase gene to the development of lordosis behavior}

The display of lordosis in response to the mounting of a stud male was clearly impaired in ArKO females that were treated with estradiol and progesterone (Fig. 5A). The same hormone treatment was effective, however, in inducing lordosis behavior in WT and HET females. Two-way ANOVA with genotype as the independent factor and tests as the repeated factor revealed a significant effect of genotype $\left(F_{(2,15)}=19.45 ; p=0.0001\right)$ and a significant effect of repeated testing $\left(F_{(4,60)}=4.57 ; p=0.0027\right)$. Post hoc analysis showed that lordosis quotients were lower in ArKO females than WT and HET females. Furthermore, lordosis quotients increased in the same way in all female groups over tests, because there was no significant test by genotype interaction $\left(F_{(8,60)}=0.74 ; p=0.65\right)$. The number of mounts received from the stud male did not differ between groups (mean \pm SEM: WT, $9.9 \pm 0.4$; HET, $9.8 \pm 0.2$; ArKO, $9.7 \pm 0.2 ; F_{(2,15)}=0.36 ; p=$ $0.70)$.

In addition, ArKO females rejected the stud male more frequently, as indicated by their lower receptivity scores, than WT 
and HET females (Fig. 5B). Two-way ANOVA with genotype as the independent factor and tests as the repeated factor indicated a significant effect of genotype $\left(F_{(2,15)}=36.0 ; p=0.0001\right)$ and a significant effect of testing $\left(F_{(4,60)}=6.59 ; p=0.0002\right)$. Post hoc analysis showed that receptivity scores were significantly lower in ArKO females than WT and HET females and increased similarly in all female groups over the course of testing, because there was no significant test by genotype interaction $\left(F_{(8,60)}=1.35 ; p=\right.$ 0.23 ) (Fig. $5 B)$.

\section{Experiment 3: olfaction test}

Overall, there was no significant difference between females of each genotype in the time it took to find the hidden cookie (mean \pm SEM: WT, $89 \pm 5$ sec; HET, $189 \pm 15 \mathrm{sec}$; ArKO, $181 \pm 21 \mathrm{sec})$. Two-way ANOVA with genotype as the independent factor and tests as the repeated factor revealed a significant effect of tests $\left(F_{(1,15)}=6.24 ; p=0.02\right)$ but no significant effect of genotype $\left(F_{(2,15)}=1.70 ; p=0.22\right)$ nor a significant test by genotype interaction $\left(F_{(2,15)}=2.44 ; p=0.12\right)$. The longer average time to find the cookie in the HET and ArKO groups reflects the poor performance of two ArKO females and one HET female but did not appear to be a characteristic of the genotype. Overall, all females found the cookie faster in the second test (mean \pm SEM: WT, $137 \pm 28$ vs $42 \pm 5$ sec; HET, $325 \pm 75$ vs $53 \pm 19$ sec; ArKO, $189 \pm 48$ vs $174 \pm 101 \mathrm{sec}$ for test 1 vs 2 , respectively). This effect of repeated testing appears to be less pronounced in ArKO females, but there was no significant test by genotype interaction $\left(F_{(2,15)}=2.44 ; p=0.12\right)$.

\section{Experiment 4: open-field test}

Overall, no differences could be detected in general locomotor activity among female groups when subjects were tested in an open field. One-way ANOVA on the number of crossings did not show any genotype differences (mean \pm SEM: WT, $66.6 \pm 9.5$; HET, $55.2 \pm 8.0$; ArKO, $\left.56.2 \pm 9.7 ; F_{(2,14)}=0.47 ; p=0.64\right)$. Furthermore, one-way ANOVA on the maximum amount of time spent immobile also did not show any genotype differences (mean \pm SEM: WT, $38 \pm 7 \mathrm{sec}$; HET, $62 \pm 14 \mathrm{sec}$; ArKO, $62 \pm$ $\left.14 \sec ; F_{(2,14)}=1.04 ; p=0.38\right)$.

\section{Experiment 5: contribution of the aromatase gene to the development of male sexual behaviors}

When treated with testosterone alone, female ArKO mice showed no male-typical sexual behaviors with an estrous female, whereas WT and, to a lesser extent, HET females readily displayed mounting and intromission-like behaviors. The addition of estradiol to the testosterone treatment stimulated a little mounting and intromission-like behavior in ArKO females, but not up to the levels shown by WT and HET females (Fig. 6). A two-way ANOVA on the number of mounts revealed a significant effect of genotype $\left(F_{(2,23)}=7.06 ; p=0.0041\right)$ and a significant hormone by genotype interaction $\left(F_{(2,23)}=6.14 ; p=0.0073\right)$. Post hoc analysis on the genotype effect showed that ArKO females displayed fewer mounts than WT and HET females. Furthermore, post hoc analysis on the hormone by genotype interaction revealed that ArKO females mounted the estrous female more frequently when treated with testosterone and estradiol, whereas the total number of mounts remained the same in WT and HET females. Two-way ANOVA on the number of intromission-like behaviors revealed a significant effect of genotype $\left(F_{(2,23)}=23.84 ; p=0.0001\right)$, a significant effect of hormone treatment $\left(F_{(1,23)}=5.36 ; p=0.03\right)$, and a significant hormone by genotype interaction $\left(F_{(2,23)}=5.90\right.$; $p=0.0085)$. Post hoc analysis of the genotype effect showed that

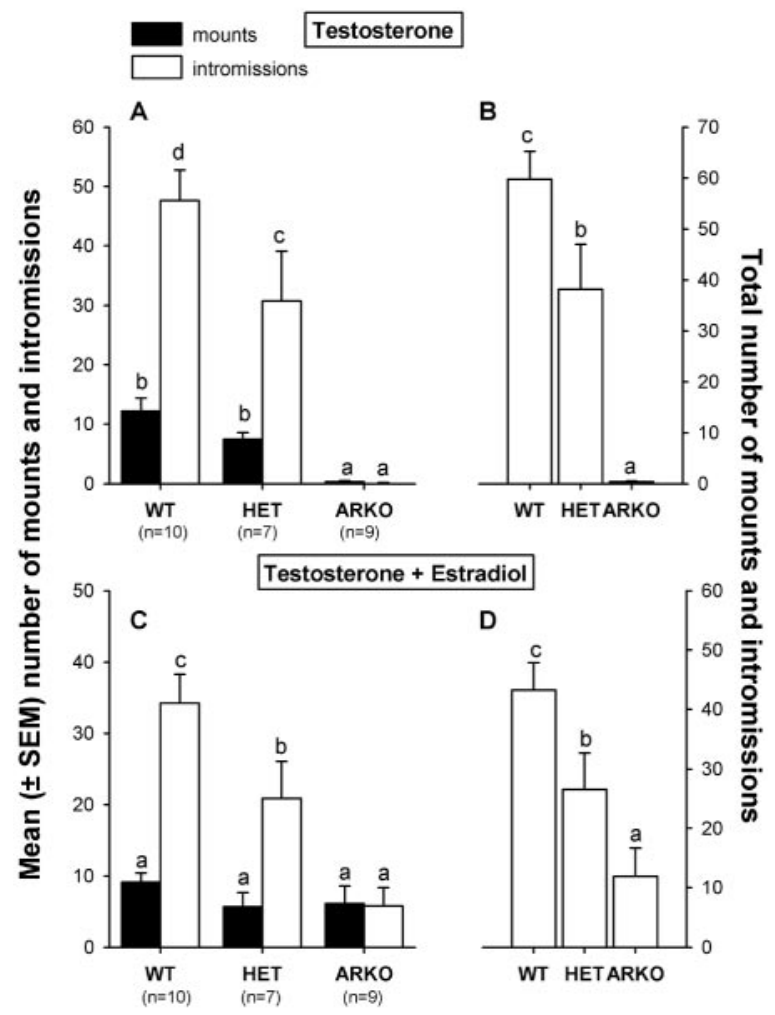

Figure 6. A, C, Mean number of mounts and intromission-like behaviors displayed by female WT, HET, and ArKO mice when paired with an estrous female. $B, D$, Total number of mounts and intromissions together. $A, B$, Results when subjects were treated with testosterone. $C, D$, Results when the same subjects also received daily injections with estradiol while remaining on testosterone. Means with different letters above them are significantly different from each other by post hoc comparisons.

ArKO females displayed fewer intromission-like behaviors compared with WT and HET females, with the latter displaying fewer intromissions than WT females. Post hoc analysis of the hormone by genotype effect showed that ArKO females displayed more intromission-like behaviors when treated with testosterone and estradiol, whereas the number of intromissions decreased in similarly treated WT and HET females.

\section{DISCUSSION}

The present study indicates that estradiol is required both during development and in adulthood for a normal expression of sociosexual behaviors in the female mouse. Female ArKO mice that are depleted of estradiol because of a targeted mutation of the aromatase gene showed aberrant sociosexual behaviors in adulthood. When treated with testosterone, ArKO females showed little motivation to investigate olfactory (both volatile and nonvolatile) and visual cues from either an estrous female or an intact male. Even when physical contact was allowed, ArKO females investigated the stimulus animals significantly less than WT subjects. These behavioral differences could have reflected differences in activation of olfactory investigation by estradiol, because testosterone treatment presumably generated higher levels of estradiol in WT than in ArKO females. To distinguish between activational and organizational effects of estradiol on olfactory investigation, the same female subjects were tested again for odor preferences after they had received estradiol treatment for several weeks in adulthood. The defects in olfactory investigation 
could, in part, be corrected with adult estradiol treatment. The motivation to investigate soiled bedding was restored in estradioltreated ArKO females. In contrast, adult estradiol treatment did not restore the motivation of ArKO females to investigate volatile odors from either stimulus animal. Furthermore, ArKO females showed little or no lordosis behavior when treated with doses of estradiol and progesterone that were behaviorally effective in WT females. These results suggest that estradiol has both organizational and activational effects on the display of olfactory investigation and sexual receptivity in female mice.

\section{Organizational effects of estrogens in female mice}

Sexual receptivity and olfactory investigations were severely impaired in female ArKO mice even after prolonged ( $>6$ weeks) treatment with estradiol in adulthood. Many rodent species, including mice, rely on olfactory cues to distinguish the sex and reproductive status of conspecifics (Brown, 1979). It is possible that ArKO females simply did not recognize the stud male as being male on the basis of his odors and as a result did not become sexually receptive. Interestingly, the lordosis impairment decreased toward the end of the tests, possibly as a result of repeated mounting and stimulation of the flanks and back of the female. The deficits in sexual receptivity might thus be caused by an impairment in olfactory recognition.

The deficit in lordosis behavior was unexpected, because male rats neonatally deprived of estradiol showed female-typical levels of sexual receptivity after treatment with estradiol and progesterone in adulthood (McEwen et al., 1977; Vreeburg et al., 1979; Fadem and Barfield, 1981; Bakker et al., 1993). These data led to the concept that the female brain develops in the absence of ovarian hormones, whereas the development of the male brain requires the presence of both testosterone and estradiol. Several studies have challenged this concept and suggested an active role for estradiol in the development of the brain in females (ToranAllerand, 1976; Döhler et al., 1984; Mack et al., 1993). The present work provides new evidence that estradiol may be required for a normal female development and thus a normal expression of sociosexual behaviors in adulthood.

It seems unlikely that the deficit in lordosis behavior can be attributed to excessive androgen action during development leading to a masculinization and defeminization of the brain. Fisher et al. (1998) reported that testosterone levels are elevated in adult ArKO females. This elevation is probably a result of the absence of a negative feedback by estradiol on the hypothalamus, as evidenced by increased levels of luteinizing hormone. However, whether testosterone levels are also elevated during development remains questionable. Basal estrogen secretion (and presumably testosterone production) by the ovaries has been shown to be undetectable during fetal stages and before day 5 after birth (Weniger, 1993; Weniger et al., 1993). However, even if testosterone levels are elevated perinatally in ArKO females, the strongest evidence against this hypothesis is that ArKO females displayed very little mounting behavior after treatment with testosterone and estradiol in adulthood, whereas similarly treated WT and HET females vigorously mounted stimulus females. Likewise, it seems unlikely that the brains of ArKO females were defeminized by excessive androgen action during development, because many studies (Naftolin et al., 1975; McEwen et al., 1977; Baum, 1979; Vreeburg et al., 1979; Fadem and Barfield, 1981; MacLusky and Naftolin, 1981; Bakker et al., 1993) have shown that estradiol and not testosterone is the hormone implicated in defeminizing the brain. For instance, male rats treated neonatally with an aromatase inhibitor but left gonadally intact (and thus exposed to testosterone) showed levels of lordosis behavior similar to those of normal females (Bakker et al., 1993). Likewise, male mice and rats carrying a mutation in the androgen receptor $(\mathrm{tfm})$ did not show any lordosis behavior after treatment with estradiol and progesterone in adulthood, suggesting that their lordotic potential was lost as a result of estrogen action during development (for review, see Olsen, 1992).

Alternatively, the impairment of lordosis behavior in ArKO females could result from their hypersensitivity to small amounts of estrogens coming from their HET mother leading to a defeminization of their adult lordotic potential. However, concentrations of free maternal estradiol in the fetuses should be very low because of the presence of high levels of estradiol-binding $\alpha$-fetoproteins in the blood. These $\alpha$-fetoproteins are thought to protect the developing female brain from being masculinized and defeminized by estradiol, and there is no reason why $\alpha$-fetoproteins would play this role differentially in WT and in ArKO subjects.

Finally, phytoestrogens potentially present in the food could freely enter the fetal brain, because they presumably do not bind to $\alpha$-fetoproteins and thus could be a significant source of estrogen action in ArKO females. Limited developmental effects of phytoestrogens on sexual behavior and neuroendocrine function have been reported in rats, although most significant effects were seen in males (Whitten et al., 1995). However, our mice were fed a mouse chow (UAR, Epinay sur Orge, France) that does not appear to contain biologically active estrogens, as revealed by its lack of effect on uterine growth and on the growth of estrogendependent cell lines (M. Huard, UAR, personal communication). Exposure of our ArKO mice to phytoestrogens was thus negligible. In conclusion, the present results are best explained by assigning an active role for estradiol in females in the development of the neural substrates that are involved, in later life, in olfactory recognition and sexual receptivity.

\section{Sexual differentiation of odor preferences in mice}

In contrast to rats (Bakker et al., 1996), odor preferences do not seem to be sexually differentiated in mice. Like male WT mice (Bakker et al., 2002), female WT mice, especially when treated with estradiol in adulthood, showed a clear preference to sniff volatile odors from an estrous female over those from an intact male. Furthermore, WT females showed high levels of male sexual behavior when paired with an estrous female, suggesting that female mice are normally masculinized. HET females displayed male sexual behaviors and odor preferences at levels that were intermediate between WT and ArKO subjects. Correspondingly, brain aromatase activity was found to be intermediate in HET females, whereas it was undetectable in ArKO females (Baillien et al., 2002). These results suggest that a female-directed odor preference and the expression of male sexual behavior are organized by aromatized metabolites of testosterone in a dosedependent manner.

\section{Main versus accessory olfactory system}

In most mammalian species, a main olfactory system and an accessory olfactory system can be distinguished neuroanatomically. In rodents, pheromones that are generally composed of nonvolatile molecules are presumably processed by the accessory olfactory system (Meredith and O'Connell, 1979), whereas nonreproductively relevant olfactory cues composed mostly of volatile molecules are processed primarily through the main olfactory 
system (O'Connell and Meredith, 1984). The present study shows that estradiol differentially affected the functioning of these two systems. Estradiol appears to be required for the development of the main olfactory system, because the deficiencies in olfactory investigation of volatile odors by ArKO females could not be corrected by prolonged estradiol treatment in adulthood. ArKO females were not anosmic, however, and could find a hidden food item by its smell as rapidly as WT and HET subjects. In contrast, estradiol is apparently not required for the development of the accessory olfactory system but is needed for its normal functioning in adulthood: treatment with estradiol of ArKO females corrected the previously observed defects in olfactory investigation of soiled bedding. Thus, estradiol has organizational effects on the main olfactory system and activational effects on the accessory olfactory system.

In conclusion, the present study using estradiol-deficient ArKO mice indicates that estradiol is required during development for the expression of sociosexual behaviors in adult female mice. The old concept that female differentiation proceeds in the absence of any hormonal influence therefore requires re-examination. The present data do not identify the developmental stage(s) (i.e., embryonic, early postnatal, and/or prepubertal and postpubertal) at which exposure to estradiol is required for a normal development of the female brain, but this question can be answered using the ArKO mouse model, because its genetic deficiency can be bypassed by administration of exogenous estradiol at specific stages of the life cycle.

\section{REFERENCES}

Baillien M, Bakker J, Honda S, Harada N, Balthazart J (2002) Aromatase activity in the brain of wild-type and ArKO mice. Soc Neurosci Abstr 28:383.4.

Bakker J, van Ophemert J, Slob AK (1993) Organization of partner preference and sexual behavior and its nocturnal rhythmicity in male rats. Behav Neurosci 107:1049-1058.

Bakker J, van Ophemert J, Slob AK (1996) Sexual differentiation of odor and partner preference in the rat. Physiol Behav 60:489-494.

Bakker J, Honda S, Harada N, Balthazart J (2002) Sexual partner preference requires a functional aromatase (Cyp19) gene in male mice. Horm Behav, in press.

Baum MJ (1979) Differentiation of coital behavior in mammals: a comparative analysis. Neurosci Biobehav Rev 3:265-284.

Brown RE (1979) Mammalian social odors: a critical review. Adv Study Behav 10:103-162.

Döhler KD, Hancke JL, Srivastava SS, Hofmann C, Shryne JE, Gorski RA (1984) Participation of estrogens in female sexual differentiation of the brain: neuroanatomical, neuroendocrine, and behavioral evidence. In: Progress in brain research, Vol 61, Sex differences in the brain (de Vries GJ, de Bruin JPC, Uylings HBM, Corner MA, eds), pp 99-117. Amsterdam: Elsevier.

Fadem BH, Barfield RJ (1981) Neonatal hormonal influences on the development of proceptive and receptive feminine sexual behavior in rats. Horm Behav 15:282-288.

Feder HH, Whalen RE (1965) Feminine behavior in neonatally castrated and estrogen-treated male rats. Science 147:306-307.

Fisher CR, Graves KH, Parlow AF, Simpson ER (1998) Characterization of mice deficient in aromatase (ArKO) because of targeted disruption of the Cyp19 gene. Proc Natl Acad Sci USA 95:6965-6970.

Fitch RH, Denenberg VH (1998) A role for ovarian hormones in sexual differentiation of the brain. Behav Brain Sci 21:311-327.

Grady KL, Phoenix CH, Young WC (1965) Role of the developing rat testis in differentiation of the neural tissues mediating mating behavior. J Comp Physiol Psychol 59:176-182.

Honda S, Harada N, Ito S, Takagi Y, Maeda S (1998) Disruption of sexual behavior in male aromatase-deficient mice lacking exons 1 and 2 of the Cyp19 gene. Biochem Biophys Res Commun 252:445-449.

Jost A (1985) Sexual organogenesis. In: Handbook of behavioral neurobiology, Vol 7, Reproduction (Adler N, Pfaff D, Goy RW, eds), pp 3-19. New York: Plenum.

Mack CM, Fitch RH, Cowell PE, Schrott LM, Denenberg VH (1993) Ovarian estrogen acts to feminize the female rat's corpus callosum. Brain Res Dev Brain Res 71:115-119.

MacLusky NJ, Naftolin F (1981) Sexual differentiation of the central nervous system. Science 211:1294-1302.

McEwen BS, Lieberburg I, Chaptal C, Krey LC (1977) Aromatization: important for sexual differentiation of the neonatal rat brain. Horm Behav 9:249-263.

Meredith M, O'Connell RJ (1979) Efferent control of stimulus access to the hamster vomeronasal organ. J Physiol (Lond) 286:301-316.

Naftolin F, Ryan KJ, Davies IJ, Reddy VV, Flores F, Petro Z, Kuhn M, White RJ, Takoaka Y, Wolin L (1975) The formation of estrogens by central neuroendocrine tissues. Recent Prog Horm Res 31:295-315.

O'Connell RJ, Meredith M (1984) Effects of volatile and nonvolatile chemical signals on male sex behaviors mediated by the main and accessory olfactory systems. Behav Neurosci 98:1083-1093.

Olsen KL (1992) Genetic influences on sexual behavior differentiation. In: Handbook of behavioral neurobiology, Vol 11, Sexual differentiation (Gerall AA, Moltz H, Ward IL, eds), pp 1-40. New York: Plenum.

Petrulis A, Johnston RE (1999) Lesions centered on the medial amygdala impair scent-marking and sex-odor recognition but spare discrimination of individual odors in female golden hamsters. Behav Neurosci 113:345-357.

Phoenix CH, Goy RW, Gerall AA, Young WC (1959) Organizing actions of prenatally administered testosterone propionate on the tissues mediating behavior in the female guinea pig. Endocrinology 65:369-382.

Smith ER, Damassa DA, Davidson JM (1977) Hormone administration: peripheral and intracranial implants. Methods Psychobiol 3:259-279.

Toran-Allerand CD (1976) Sex steroids and the development of the newborn mouse hypothalamus and preoptic area in vitro: implications for sexual differentiation. Brain Res 106:407-412.

Vreeburg JTM, van der Vaart PDM, van der Schoot P (1979) Prevention of central defeminization but not masculinization in male rats by inhibition neonatally of oestrogen biosynthesis. J Endocrinol 74:375-382.

Weniger JP (1993) Estrogen production by fetal rat gonads. J Steroid Biochem Mol Biol 44:459-462.

Weniger JP, Zeis A, Chouraqui J (1993) Estrogen production by fetal and infantile rat ovaries. Reprod Nutr Dev 33:129-136.

Wersinger SR, Haisenleder DJ, Lubahn DB, Rissman EF (1999) Steroid feedback on gonadotropin release and pituitary gonadotropin subunit mRNA in mice lacking a functional estrogen receptor $\alpha$. Endocrine 11:137-143.

Whitten PL, Lewis C, Russell E, Naftolin F (1995) Potential adverse effects of phytoestrogens. J Nutr 125:771S-776S. 